\title{
Adolescent motherhood in Bangladesh: Evidence from 2007 BDHS data
}

\author{
S.M. Mostafa Kamal \\ Department of Mathematics \\ Islamic University, Kushtia (Bangladesh) \\ kamaliubd@yahoo.com
}

\begin{abstract}
This paper examines the factors affecting adolescent motherhood in Bangladesh using the 2007 Bangladesh Demographic and Health Survey data. Overall, 69.3 per cent of the married adolescents began childbearing. Among them 56.4 per cent were already mothers and 12.9 per cent were pregnant for the first time. Of the adult married women age 20-49, 62.1 per cent initiated childbearing before age 19. The multiple logistic regression analyses revealed that women's education, husband's education, place of residence, ever use of contraceptive method, religion, wealth and region are important determinants of adolescent motherhood in Bangladesh.
\end{abstract} Keywords: adolescent motherhood, Bangladesh, education, fertility.

\section{Résumé}

À partir des données d'une enquête sur la démographie et la santé du Bangladesh en 2007, cet article examine les facteurs ayant une incidence sur la maternité chez les adolescentes an Bangladesh. Dans l'ensemble, 69,3\% des adolescentes mariées ont commencé à avoir des enfants. Parmi celles-ci, 56,4\% avaient déjà des enfants et 12,9\% étaient enceintes pour la première fois. Chez les femmes adultes mariées âgées de 20 à 49 ans, 62,1\% ont commencé à avoir des enfants avant d'avoir 19 ans. Les multiples analyses de régression logistiques ont indiqué que l'éducation de la femme, l'éducation du mari, le lieu de résidence, la méthode éventuelle de contraception, la religion, la richesse et la région étaient des facteurs déterminants importants de maternité chez. les adolescentes au Bangladesh.

Mots-clés : maternité chez les adolescentes, Bangladesh, éducation, fertilité. 


\section{Introduction}

Over the last three decades the world has witnessed a dramatic change in reproductive behaviour of women in Bangladesh. The total fertility rate (TFR) has dropped dramatically from a high level of 6.3 births per woman in the mid-1970s to 2.7 births in 2007. Meanwhile, the contraceptive prevalence rate (CPR) has increased from a low level of 7.7 per cent to a high level of 58.1 per cent (NIPORT et al. 2009). The achievements in reproductive behaviour of Bangladeshi women have been viewed as a "success in a challenging environment" (Cleland et al. 1994). However, these average pictures hide the wide variations in reproductive behaviour that are prevailing across regions and subgroups of Bangladeshi women by socioeconomic strata. One such behaviour is adolescent childbearing.

In recent decades, teenage pregnancy and teenage childbearing have captured a lot of research interest in both developed and developing countries due to the socioeconomic and health consequences for both mother and child. Despite substantial development in Human Development Indicators (HDI) in the recent past decades, the patterns of early marriage and early childbearing are still persistent in Bangladesh. In fact, early age at marriage and early childbearing are customs in the patriarchal Bangladeshi culture. While studies on fertility and contraceptive issues are enormous in Bangladesh, until recently, socioeconomic factors affecting adolescent childbearing has received very little attention among researchers and policymakers.

Frequently experts have expressed concern about the negative social, health and economic consequences of teenage marriage, adolescent childbearing, unintended pregnancies and in some societies, high levels of pre and extramarital conceptions (Bogue et al. 1977). Although such issues concerning adolescents are much publicized throughout the developed countries (ESCAP 1992), the concepts are relatively new in many developing countries, including Bangladesh. Teenage motherhood is still regarded as a public health problem or a "social epidemic" by public officials, physicians, the press and the general public. In addition, the common sense view still tends to regard adolescent pregnancy as a cause of poverty rather than as a consequence of it, and of the lack of resources and alternative projects (Gogna et al. 2008).

Adolescence is a period of turbulence. This is a period with special importance in the life course of an individual (Sutay 2010). Many important life events and health-damaging behaviours start during adolescence (Khan and Mishra 2008). The transition to motherhood is a pivotal time of psychological, developmental, and biological change in a mother's life (Birkeland et al. 2005; Devine et al. 2000; Zabielski 1994; Deutsch et al. 1988; Jennings and Edmundson 1980). Long-term demographic effects of adolescent fertility may include larger completed family sizes as the timing of a first birth is usually an indicator of future fertility patterns (Menken 1980; Senderowitz and Paxman 1985; Voydanoff and Donnelly 1990; Wulf and Singh 1991; as well as 1987 data from the Commission on Behavioral and Social Sciences and Education). Unintended and mistimed pregnancies are also reported to be higher among 
the teenage mothers (Magadi et al. 2003), which subsumed a significant proportion for increased level of fertility.

Although most literature supports the notion that teenage childbearing is generally associated with higher risk of adverse health outcomes for mother and newborn baby, some other studies shows controversial results. Findings from studies in developing countries through less rigorous analytic methods suggest that adolescent maternity is causally associated with increased poor obstetric indicators: antenatal care services utilization and delivery by skilled personnel (Magadi et al. 2003; Wasunna and Mohammed 2002; Alam 2000; Orvos et al. 1999). Health consequences included higher levels of blood pressure, toxaemia, anaemia, excessive bleeding, prolonged labour and premature delivery (Zabin and Kiragu 1998), higher incidence of low birth weight, stillbirth and perinatal mortality (Phipps and Sowers 2002; Lee et al. 1998). Furthermore, teenage motherhood than that of adult has negative social, economic and health consequences for mothers and their children (AGI 1998; Gage 1995; Hayes 1987).

In contrast, studies from developed countries found no significant increased adverse obstetric and child health outcomes among teenagers compared to older mothers (Smith and Pell 2001; Tsai et al. 2001; Jimenez et al. 2000). Such similarity of obstetric outcomes between adolescent and adult mothers in the developed countries is mainly credited to availability and easy accessibility in obstetric care and social contexts of pregnancies (Foix-L'Helias and Blondel 2000). Thus, there is dearth of systematic documentation of adverse social, economic and obstetric outcomes among the teenage mothers of developing countries. This may be partly attributed to the fact that in developing countries the teenagers generally experience poorer maternal health indicators to a large extent than those of developed countries.

In spite of rapid fertility transition in Bangladesh, teenage fertility has not been changed at the same pace and magnitude. Although the age-specific fertility rate of women aged 20-49 decreased consistently during 1993-1994 to 2007, the contribution to the country's level of TFR by adolescents has remained still high. According to the 2007 Bangladesh Demographic and Health Survey (BDHS), almost one fourth (23.3 per cent) of the TFR was attributed to the adolescents. In 2007, the fertility rate among adolescents was 126 per 1,000 , which was higher than among women aged 30-49. In rural areas, the fertility rate among married teen agers was 137 per 1,000 (NIPORT et al. 2009), which was second highest among all age groups of women. In Bangladesh, childbearing outside of marriage is illegal and is not socially acceptable. In societies where child births are confined to marriage, age at first marriage marks the onset of the period of offspring procreation, and therefore, age at first marriage is considered the prime determinant of fertility.

Woman's age at first marriage is an important indicator of exposure of women to the risk of pregnancy and is therefore important for understanding the timing of childbearing and fertility pattern where childbearing occurs only within wedlock. Early pregnancy possesses great health risks for a young woman and, if she carries the pregnancy to term, for her infant; these risks are exacerbated by poverty and inadequate access to maternal and child health 
services (Sing and Samara 1996). Studies reveal that, the females' age at first marriage in Bangladesh is still one of the lowest in the world. Traditionally, Bangladesh has one of the highest rates of child marriage worldwide (Barkat and Majid 2003) and age at first birth remains relatively low (Bosch et al. 2008). In a study conducted on 40 developing countries, the median age at first marriage of Bangladeshi women was reported to be 14.1 years, the lowest amongst the study countries (Singh and Samara 1996).

The studies conducted so far on fertility related issues in Bangladesh mostly focused to examining the causal relationship between age at first marriage, contraceptives, unintended pregnancies etc. Little attention has been paid to understand adolescent childbearing. Taking "the context" seriously into account, this article therefore aims at identifying priorities for action and providing useful data and ideas for the design of specific interventions that respond to the needs of different sub-groups of women. Thus, this study aims to examine the association between adolescent childbearing and various socioeconomic factors and also investigate to what extent the factors influence adolescent motherhood among women of Bangladesh.

\section{Data and methods}

The study used the nationally representative 2007 BDHS data. The 2007 BDHS was a survey of 10,996 women age 15-49 and 3,771 men age 15-54 from 10,400 households covering 361 sample points (clusters) throughout Bangladesh, 134 in urban areas and 227 in the rural areas. The survey was carried out following a standard manner under the authority of the National Institute for Population Research and Training (NIPORT) of the Ministry of Health and Family Welfare. Survey sample was designed using scientific sampling probability. The survey gathered detailed information on fertility levels, marriage, fertility preference, awareness and use of family planning methods, childhood mortality and causes of death of children under five, maternal and child health, HIV/AIDS related knowledge, behaviour etc. Information on the timing of first birth was collected from women in the standard DHS individual module. A detailed birth history was recorded including all live births performed by women along with the age at first birth, birth date, year of birth, sex of child, survival status of each child etc. The details of the survey are provided in the report (NIPORT et al. 2009).

In this study, the sample was made weighted by corresponding weighting factor provided for each of the women in survey data. The first section of the study deals with married adolescents to examine their childbearing status. The second section of the study examines the determinants of teenage motherhood among adult women. The first section would help in understanding present situation of reproductive behaviour of the adolescents, in particular, the childbearing status of the married female adolescents and the second part would help in driving up understanding the patterns and determinants of adolescent childbearing of the adult women age $20-49$.

Both bivariate and multivariate statistical analyses were employed to assess the association between teenage motherhood and socioeconomic and demo- 
graphic characteristics of the respondents. A binary response was created for the outcome variable "teenage motherhood," i.e., "motherhood before age 19 " for the adult women by the way that, if a woman had had given first childbirth at age 18 or before, then she was coded as ' 1 ' and ' 0 ' for otherwise. The cut-off point was selected 18 on the basis of the mean age at first birth (17.8 years) of the respondents age 20-49, which was very close to 18 . To assess the association between the dependent variable and the independent variables in this study, we performed chi-square tests. Multiple logistic regression was thought to be suitable to assess the net effect of the factors associated with adolescent childbearing. To ease the interpretations, our results have been expressed by estimated odds ratios (OR) with 95 per cent confidence interval (CI). All of the statistical analyses in this study have been performed by SPSS v17 software.

\section{Results}

\section{Profile of the respondents}

Table 1 shows the percentage distribution of women by their background characteristics. The mean age and age at first marriage were 30.4 years and 15.2 years respectively. Mean age at first birth performed by the women was 17.8 years for adults and 15.9 years for adolescents respectively (these are not shown in the Table 1$)$. Slightly over one-fifth (22.6 per cent) of the women were from urban and 77.4 per cent were from rural areas. More than one-third had no formal education and over one-third had at least secondary level of education. With regard to husband's education, 35.6 per cent had no formal education, while almost two-fifths had at least secondary level of education. The vast majorities were Muslims. Of the respondents, 88.1 per cent were from male headed households. Four in five women had ever used any contraceptive methods and 45.4 per cent ever discussed on family planning with their husbands. About one in three (32.1 per cent) were currently working women. In terms of wealth index, slightly less than two-fifths (38.8 per cent) were from poor and over two-fifths (41.2 per cent) were from rich households. The more women were from Dhaka division, followed by Rajshahi, Chittagong, Khulna, Sylhet and Barisal divisions respectively.

\section{Pregnancy and motherhood among married teenagers}

Table 2 shows the weighted percentage of childbearing status of ever married adolescents by various socioeconomic and demographic factors. Overall, 56.4 per cent of the adolescents were already mothers and another 12.9 per cent were pregnant for the first time. This implies that 69.3 per cent of the Bangladeshi married adolescents experience pregnancy in their teen ages. To some extent, adolescent sub-fecundity rather than infertility may be responsible for not childbearing in teen ages of the adolescents who were not mother or pregnant. According to BDHS report, almost one-third of the adolescents begin childbearing in their teen ages irrespective of their marital status. 
Table 1. Weighted percentage of ever married women aged 15-49 by sociodemographic characteristics, Bangladesh 2007.

\begin{tabular}{|c|c|c|c|}
\hline & Characteristics & $\mathrm{N}$ & $\%$ \\
\hline \multicolumn{4}{|l|}{ Current age } \\
\hline & $15-19$ & 1,424 & 13.0 \\
\hline & $20-24$ & 2,175 & 19.8 \\
\hline & $25-29$ & 1,931 & 17.6 \\
\hline & $30-34$ & 1,660 & 15.1 \\
\hline & $35-39$ & 1,564 & 14.2 \\
\hline & $40-44$ & 1,213 & 11.0 \\
\hline & $45-49$ & 1,030 & 9.4 \\
\hline \multicolumn{4}{|l|}{ Place of residence } \\
\hline & Urban & 2,482 & 22.6 \\
\hline & Rural & 8,514 & 77.4 \\
\hline \multicolumn{4}{|l|}{ Women's education } \\
\hline & No education & 3,746 & 34.1 \\
\hline & Primary & 3,263 & 29.7 \\
\hline & Secondary+ & 3,986 & 36.3 \\
\hline Husband's education & No education & 3,915 & 35.6 \\
\hline & Primary & 2,888 & 26.3 \\
\hline & Secondary + & 4,180 & 38.1 \\
\hline \multicolumn{4}{|l|}{ Religion } \\
\hline & Islam & 10,005 & 91.0 \\
\hline & Others & 991 & 9.0 \\
\hline \multicolumn{4}{|l|}{ Sex of household head } \\
\hline & Female & 1,311 & 11.9 \\
\hline \multicolumn{4}{|l|}{ Ever used FP method } \\
\hline & No & 2,153 & 19.6 \\
\hline & Yes & 8,843 & 80.4 \\
\hline \multicolumn{4}{|l|}{ Ever discussed on FP } \\
\hline & No & 5,563 & 54.6 \\
\hline & Yes & 4,622 & 45.4 \\
\hline \multicolumn{2}{|l|}{ Women's work status } & 7,459 & 67.9 \\
\hline & Non-working & 3,533 & 32.1 \\
\hline \multicolumn{4}{|l|}{ Wealth index } \\
\hline & Poorest & 2,115 & 19.2 \\
\hline & Poorer & 2,157 & 19.6 \\
\hline & Middle & 2,186 & 19.9 \\
\hline & Richer & 2,259 & 20.5 \\
\hline & Richest & 2,278 & 20.7 \\
\hline \multicolumn{4}{|l|}{ Region } \\
\hline & Barisal & 662 & 6.0 \\
\hline & Chittagong & 2,023 & 18.4 \\
\hline & Dhaka & 3,431 & 31.2 \\
\hline & Khulna & 1,396 & 12.7 \\
\hline & Rajshahi & 2,776 & 25.2 \\
\hline & Sylhet & 707 & 6.4 \\
\hline Total & & 10,996 & 100.0 \\
\hline
\end{tabular}


Table 2. Weighted percentage of ever married adolescent women aged 15-19 by childbearing status and socio-demographic characteristics, Bangladesh 2007.

\begin{tabular}{|c|c|c|c|c|c|c|}
\hline \multirow[b]{2}{*}{ Characteristics } & \multirow[b]{2}{*}{$\mathrm{N}$} & \multicolumn{2}{|c|}{$\begin{array}{c}\text { Childbearing } \\
\text { status }\end{array}$} & \multicolumn{3}{|c|}{ Begun childbearing } \\
\hline & & Mother & $\begin{array}{l}\text { Pregnant } \\
\text { for the } \\
\text { first time }\end{array}$ & No & Yes & $\begin{array}{l}\text { chi- } \\
\text { square }\end{array}$ \\
\hline Current age & & & & & & $65.07 * * *$ \\
\hline $15-17$ & 621 & 42.7 & 15.4 & 42.0 & 58.0 & \\
\hline $18-19$ & 803 & 67.1 & 10.9 & 22.1 & 77.9 & \\
\hline Place of residence & & & & & & 0.16 \\
\hline Urban & 252 & 50.7 & 17.4 & 31.9 & 68.1 & \\
\hline Rural & 1,172 & 57.7 & 11.8 & 30.5 & 69.5 & \\
\hline Women's education & & & & & & $12.16 * * *$ \\
\hline No education & 142 & 66.4 & 13.3 & 20.4 & 79.6 & \\
\hline Primary & 407 & 61.6 & 10.4 & 28.0 & 72.0 & \\
\hline Secondary+ & 875 & 52.4 & 13.9 & 33.7 & 66.3 & \\
\hline Husband's education & & & & & & $9.51 * *$ \\
\hline No education & 363 & 66.3 & 8.9 & 24.8 & 75.2 & \\
\hline Primary & 479 & 57.7 & 11.2 & 31.1 & 68.9 & \\
\hline Secondary+ & 578 & 49.2 & 16.4 & 34.3 & 65.7 & \\
\hline Religion & & & & & & 0.15 \\
\hline Islam & 1,335 & 57.0 & 12.4 & 30.6 & 69.4 & \\
\hline Others & 89 & 48.7 & 18.7 & 32.6 & 67.4 & \\
\hline Sex of household head & & & & & & 0.01 \\
\hline Male & 1,309 & 56.4 & 12.9 & 30.7 & 69.3 & \\
\hline Female & 115 & 57.3 & 12.2 & 30.5 & 69.5 & \\
\hline Ever used FP method & & & & & & $32.15 * * *$ \\
\hline No & 464 & 38.9 & 20.4 & 40.7 & 59.3 & \\
\hline Yes & 960 & 64.9 & 9.2 & 25.9 & 74.1 & \\
\hline Ever discussed on FP & & & & & & 0.16 \\
\hline No & 689 & 50.3 & 19.4 & 30.3 & 69.7 & \\
\hline Yes & 687 & 63.5 & 7.2 & 29.3 & 70.7 & \\
\hline Women's work status & & & & & & 0.84 \\
\hline Working & 1,170 & 54.9 & 13.8 & 31.3 & 68.7 & \\
\hline Non-working & 254 & 63.4 & 8.4 & 28.2 & 71.8 & \\
\hline Wealth index & & & & & & $15.18 * *$ \\
\hline Poorest & 238 & 62.6 & 11.6 & 25.8 & 74.2 & \\
\hline Poorer & 322 & 62.8 & 10.0 & 27.2 & 72.8 & \\
\hline Middle & 324 & 53.7 & 15.1 & 31.2 & 68.8 & \\
\hline Richer & 305 & 57.1 & 12.7 & 30.2 & 69.8 & \\
\hline Richest & 234 & 44.5 & 15.0 & 40.5 & 59.5 & \\
\hline Region & & & & & & $14.94 * *$ \\
\hline Barisal & 86 & 52.1 & 10.0 & 37.9 & 62.1 & \\
\hline Chittagong & 257 & 57.2 & 14.4 & 28.4 & 71.6 & \\
\hline Dhaka & 428 & 53.9 & 12.7 & 33.4 & 66.6 & \\
\hline Khulna & 177 & 49.8 & 12.1 & 38.2 & 61.8 & \\
\hline Rajshahi & 396 & 61.4 & 13.2 & 25.4 & 74.6 & \\
\hline Sylhet & 80 & 62.3 & 11.3 & 26.4 & 73.6 & \\
\hline Total & 1,424 & 56.4 & 12.9 & 30.7 & 69.3 & \\
\hline
\end{tabular}

Note: ${ }^{* * *} \mathrm{p}<0.001$; and $* * \mathrm{p}<0.01$. 
Age was positively associated with adolescent childbearing. Of the married adolescents age 15-17 and 18-19, 58.0 per cent and 77.9 per cent, respectively, had begun childbearing. The rural-urban differentials in childbearing among teenagers showed that the proportion of childbearing adolescents was only 1.1 per cent higher in rural than urban areas. However, the association was found to be not significant. The level of education of both wives and husbands, as expected, showed to have significant negative association with childbearing in teen ages. The higher the level of education, the lower was the prevalence of childbearing among the adolescents.

The difference of prevalence of teenage childbearing by religion, sex of household head, working status of women and inter-spousal communication on family planning was found to be minimal and not significant. Ever use of family planning (method showed that the proportion of adolescent childbearing was significantly higher among those who had ever used any contraceptive method than those who never used any family planning method. A significant inverse association was observed between adolescent childbearing and wealth index. Administrative regions showed significant association with childbearing among adolescents. The prevalence of childbearing was more in Rajshahi division, followed by Sylhet, Chittagong, Dhaka, Barisal and Khulna division respectively.

\section{Prevalence of planned and unintended pregnancy among adolescents}

The 2007 BDHS recorded all births occurred during the last five years preceding the survey. All eligible women were asked whether their last birth was wanted then, wanted later or wanted not at all. This question provided a powerful indicator of the degree to which adolescents successfully control fertility. The most recent birth or pregnancy is hereafter termed as the "most recent pregnancy." The pregnancies reported as wanted later or not wanted at all have been termed as "unintended" or "mistimed." The information on the latest pregnancy reported by the adolescents has been presented in Table 3. As shown in the table, 75.3 per cent of the most recent pregnancies were planned and 24.7 per cent of those were unintended. The age categories for adolescents showed significant difference between wanted and unintended births. The prevalence of unintended pregnancy was higher by 8.1 per cent among adolescents aged 15-17 than those aged 18-19.

Table 3. Percentage of adolescents who gave at least one birth in the last five years preceding the survey by intention status, Bangladesh 2007.

\begin{tabular}{lrrrr}
\hline \multirow{2}{*}{ Birth intention } & \multirow{2}{*}{$\mathrm{N}$} & \multicolumn{2}{c}{ Current age** } & \multirow{2}{*}{ Total } \\
\cline { 3 - 4 } & & $15-17$ & $18-19$ & \\
\hline Intended & 739 & 70.1 & 78.3 & 75.3 \\
Mistimed & 242 & 29.9 & 21.7 & 24.7 \\
\hline Total & 981 & 100.0 & 100.0 & 100.0 \\
\hline
\end{tabular}

Note: Level of significance $* * \mathrm{p}<0.01$. 
Table 4. Weighted percentage of ever married adult women aged 20-49 by childbearing status and socio-demographic characteristics, Bangladesh 2007.

\begin{tabular}{|c|c|c|c|c|c|c|}
\hline \multirow[b]{2}{*}{ Characteristics } & \multirow[b]{2}{*}{$\mathrm{N}$} & \multicolumn{2}{|c|}{$\begin{array}{c}\text { Childbearing } \\
\text { status }\end{array}$} & \multicolumn{3}{|c|}{$\begin{array}{c}\text { Begun childbearing before } \\
\text { age } 19\end{array}$} \\
\hline & & Mother & $\begin{array}{l}\text { Pregnant } \\
\text { for the } \\
\text { first time }\end{array}$ & No & Yes & chi-square \\
\hline Current age & & & & & & $21.76 * * *$ \\
\hline $20-24$ & 2175 & 87.3 & 3.6 & 41.1 & 58.9 & \\
\hline $25-29$ & 1931 & 95.5 & 0.6 & 36.9 & 63.1 & \\
\hline $30-34$ & 1660 & 97.1 & 0.2 & 37.2 & 62.8 & \\
\hline $35-39$ & 1564 & 98.0 & 0.0 & 39.8 & 60.2 & \\
\hline $40-44$ & 1213 & 98.1 & 0.0 & 35.7 & 64.3 & \\
\hline $45-49$ & 1030 & 97.4 & 0.0 & 34.1 & 65.9 & \\
\hline Place of residence & & & & & & $84.14 * * *$ \\
\hline Urban & 2230 & 93.3 & 1.4 & 46.2 & 53.8 & \\
\hline Rural & 7342 & 95.3 & 0.8 & 35.4 & 64.6 & \\
\hline Women's education & & & & & & $428.10 * * *$ \\
\hline No education & 3603 & 96.3 & 0.2 & 30.5 & 69.5 & \\
\hline Primary & 2856 & 96.2 & 0.8 & 31.2 & 68.8 & \\
\hline Secondary+ & 3111 & 92.0 & 2.0 & 52.7 & 47.3 & \\
\hline Husband's education & & & & & & $264.26 * * *$ \\
\hline No education & 3552 & 95.9 & 0.5 & 31.2 & 68.8 & \\
\hline Primary & 2409 & 95.8 & 1.0 & 32.3 & 67.7 & \\
\hline Secondary+ & 3602 & 93.2 & 1.4 & 48.3 & 51.7 & \\
\hline Religion & & & & & & $61.54 * * *$ \\
\hline Islam & 8670 & 95.0 & 1.0 & 36.7 & 63.3 & \\
\hline Others & 902 & 93.8 & 0.9 & 50.0 & 50.0 & \\
\hline Sex of household he & & & & & & 1.82 \\
\hline Male & 8376 & 95.0 & 1.0 & 37.7 & 62.3 & \\
\hline Female & 1196 & 94.3 & 1.1 & 39.7 & 60.3 & \\
\hline Ever used FP metho & & & & & & $267.05 * * *$ \\
\hline No & 1689 & 81.8 & 3.1 & 55.4 & 44.6 & \\
\hline Yes & 7883 & 97.7 & 0.5 & 34.2 & 65.8 & \\
\hline Ever discussed on F & & & & & & 0.68 \\
\hline No & 4874 & 93.7 & 1.3 & 38.3 & 61.7 & \\
\hline Yes & 3935 & 97.3 & 0.7 & 37.4 & 62.6 & \\
\hline Women's work statu & & & & & & $45.14 * * *$ \\
\hline Working & 6289 & 94.6 & 1.3 & 40.4 & 59.6 & \\
\hline Non-working & 3279 & 95.4 & 0.3 & 33.3 & 66.7 & \\
\hline Wealth index & & & & & & $281.43 * * *$ \\
\hline Poorest & 1876 & 96.6 & 0.6 & 27.8 & 72.2 & \\
\hline Poorer & 1835 & 95.7 & 0.7 & 33.4 & 66.6 & \\
\hline Middle & 1862 & 95.5 & 0.9 & 35.3 & 64.7 & \\
\hline Richer & 1955 & 94.6 & 0.7 & 39.5 & 60.5 & \\
\hline Richest & 2044 & 92.2 & 1.8 & 52.2 & 47.8 & \\
\hline Region & & & & & & $115.11 * * *$ \\
\hline Barisal & 577 & 96.2 & 0.7 & 34.8 & 65.2 & \\
\hline Chittagong & 1766 & 95.0 & 0.9 & 42.9 & 57.1 & \\
\hline Dhaka & 3003 & 94.6 & 1.1 & 38.7 & 61.3 & \\
\hline Khulna & 1219 & 95.3 & 0.4 & 36.1 & 63.9 & \\
\hline Rajshahi & 2380 & 95.1 & 0.9 & 31.4 & 68.6 & \\
\hline Sylhet & 627 & 93.0 & 2.0 & 51.4 & 48.6 & \\
\hline Total & 9,572 & 94.9 & 1.0 & 37.9 & 62.1 & \\
\hline
\end{tabular}

Note: Level of significance $* * * \mathrm{p}<0.001$. 


\section{Adolescent motherhood among adults}

This section of the study deals with adolescent motherhood among adult women aged 20-49. Table 4 shows the differentials of childbearing at teen ages by various socioeconomic and demographic factors. The table depicts that motherhood among adult women aged thirty five or more is universal. Among women aged 20-45, 94.9 per cent were already mothers and other 1.0 per cent started childbearing. Of the women age $20-25,87.3$ per cent were already mothers and other 3.6 per cent were pregnant for the first time. It is notable to mention here that, by the end of 34 , almost all women become mothers in Bangladesh. Overall, 62.1 per cent of the women started childbearing before they reach at age 19 .

Women's age showed to have significant association with motherhood before age 19. Among women aged 45-49, slightly less than three out of four had had experience of childbearing at adolescence. The proportion of adolescent motherhood amongst the younger women age 20-24 was lowest. Besides, motherhood before age 19 consistently decreased with the decrease of age of women up to age 35-39 and then again started to increase. Thus, age cohorts of women showed fluctuations in the prevalence of motherhood at teen ages. The place of residence showed significant association with teenage motherhood, with the proportion being higher in rural than urban areas.

Level of education for both wives and husbands showed to have significant inverse association with teenage motherhood. The prevalence of teenage childbearing was more prevalent among lower educated women and among those with lower educated husbands. More than two-thirds of the women with no formal education had had experience of childbirth in their age below nineteen. The proportion was almost same for women with husbands having no formal education. Less than half of the women who had at least secondary level of education started childbearing at their age 18 or below. The proportion was little higher among women whose husbands had same level of education.

The prevalence of adolescent childbearing was more common among the Muslim women than their peer non-Muslim counterparts. Sex of household head and husband-wife discussion on family planning did not show to have significant association with adolescent motherhood. Ever use of contraception was positively associated with teenage motherhood. Women's current work status showed weak association with teenage pregnancy. Wealth index showed significant negative association with teenage childbearing. 72.2 per cent of the poorest women started childbearing at their age 18 or below, while less than half of the women with richest wealth quintile had had experience of teenage motherhood. Teenage motherhood varied significantly across the regions of the country. The rate of adolescent motherhood was more frequent in Rajshahi division while the prevalence of teenage pregnancy was lowest amongst the women of Sylhet division. 
Table 5. Logistic regression results of starting childbearing among adolescent women by background characteristics, Bangladesh 2007.

\begin{tabular}{|c|c|c|c|}
\hline \multirow{2}{*}{ Characteristics } & \multirow{2}{*}{ OR } & \multicolumn{2}{|c|}{$95 \% \mathrm{CI}$} \\
\hline & & Lower & Upper \\
\hline \multicolumn{4}{|l|}{ Current age } \\
\hline $15-17$ & Reference & - & - \\
\hline $18-19$ & $2.639 * * *$ & 2.072 & 3.362 \\
\hline \multicolumn{4}{|l|}{ Place of residence } \\
\hline Urban & Reference & - & - \\
\hline Rural & $1.336 \dagger$ & 0.925 & 1.928 \\
\hline \multicolumn{4}{|l|}{ Women's education } \\
\hline No education & Reference & - & - \\
\hline Primary & $0.650 \dagger$ & 0.396 & 1.067 \\
\hline Secondary+ & $0.526^{* *}$ & 0.321 & 0.861 \\
\hline \multicolumn{4}{|l|}{ Husband's education } \\
\hline No education & Reference & - & - \\
\hline Primary & $0.766 \dagger$ & 0.544 & 1.080 \\
\hline Secondary+ & $0.733 \dagger$ & 0.508 & 1.057 \\
\hline \multicolumn{4}{|c|}{ Ever used FP method } \\
\hline No & Reference & - & - \\
\hline Yes & $2.598 * * *$ & 1.980 & 3.409 \\
\hline \multicolumn{4}{|l|}{ Wealth index } \\
\hline Poorest & Reference & - & - \\
\hline Poorer & 0.984 & 0.656 & 1.476 \\
\hline Middle & 0.805 & 0.531 & 1.221 \\
\hline Richer & 0.875 & 0.566 & 1.354 \\
\hline Richest & $0.420 * * *$ & 0.254 & 0.693 \\
\hline \multicolumn{4}{|l|}{ Region } \\
\hline Barisal & Reference & - & - \\
\hline Chittagong & $2.147^{* *}$ & 1.230 & 3.748 \\
\hline Dhaka & 1.343 & 0.798 & 2.259 \\
\hline Khulna & 1.046 & 0.594 & 1.843 \\
\hline Rajshahi & $1.858 * *$ & 1.105 & 3.124 \\
\hline Sylhet & $2.560 * *$ & 1.245 & 5.263 \\
\hline
\end{tabular}

Note: Level of significance ${ }^{* * *} p<0.001 ; * * p<0.01$; and $\dagger p<0.10$.

\section{Results of multivariate analyses}

Table 5 and Table 6 demonstrate the effect of socio-demographic characteristics of childbearing status among married adolescents and adults respectively. The results obtained in multivariate analysis are consistent with those of bivariate analysis. Age showed to have net effect on the onset of childbearing. The adolescents aged 18-19 were more likely to begin childbearing compared to those aged 15-17. Table 5 shows that women aged 30-34, 35-39 and 40-44 were significantly less likely to start childbearing before age 19 compared to the women aged 45-49. The difference of likelihood to be a mother at teen ages between young woman aged 20-29 and 45-49 was not found to be significant. 
Table 6. Logistic regression results of adolescent childbearing among adult women aged $20-49$ by background characteristics, Bangladesh 2007.

\begin{tabular}{|c|c|c|c|}
\hline \multirow{2}{*}{ Characteristics } & \multirow{2}{*}{ Odds ratio } & \multicolumn{2}{|c|}{$95 \% \mathrm{CI}$} \\
\hline & & Lower & Upper \\
\hline \multicolumn{4}{|l|}{ Current age } \\
\hline $20-24$ & 0.887 & 0.746 & 1.054 \\
\hline $25-29$ & 0.882 & 0.742 & 1.049 \\
\hline $30-34$ & $0.755^{* * *}$ & 0.633 & 0.900 \\
\hline $35-39$ & $0.687 * * *$ & 0.576 & 0.818 \\
\hline $40-44$ & $0.838 *$ & 0.696 & 1.008 \\
\hline $45-49$ & Reference & - & - \\
\hline \multicolumn{4}{|l|}{ Place of residence } \\
\hline Urban & Reference & - & - \\
\hline Rural & $1.212 * * *$ & 1.074 & 1.367 \\
\hline \multicolumn{4}{|l|}{ Women's education } \\
\hline No education & Reference & - & - \\
\hline Primary & 0.924 & 0.821 & 1.041 \\
\hline Secondary+ & $0.431 * * *$ & 0.374 & 0.496 \\
\hline \multicolumn{4}{|l|}{ Husband's education } \\
\hline No education & Reference & - & - \\
\hline Primary & 1.088 & 0.963 & 1.229 \\
\hline Secondary+ & $0.791 * * *$ & 0.696 & 0.900 \\
\hline \multicolumn{4}{|l|}{ Religion } \\
\hline Islam & Reference & - & - \\
\hline Others & $0.547 * * *$ & 0.472 & 0.633 \\
\hline \multicolumn{4}{|l|}{ Ever used FP method } \\
\hline No & Reference & - & - \\
\hline Yes & $2.938 * * *$ & 2.610 & 3.308 \\
\hline \multicolumn{4}{|l|}{ Work status } \\
\hline Working & Reference & - & - \\
\hline Not working & $1.114 *$ & 1.011 & 1.228 \\
\hline \multicolumn{4}{|l|}{ Wealth index } \\
\hline Poorest & Reference & - & - \\
\hline Poorer & $0.873^{*}$ & 0.753 & 1.012 \\
\hline Middle & $0.874^{*}$ & 0.752 & 1.015 \\
\hline Richer & $0.863 *$ & 0.739 & 1.008 \\
\hline Richest & $0.687 * * *$ & 0.575 & 0.820 \\
\hline \multicolumn{4}{|l|}{ Region } \\
\hline Barisal & Reference & 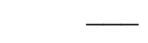 & - \\
\hline Chittagong & 0.865 & 0.702 & 1.066 \\
\hline Dhaka & 0.901 & 0.737 & 1.101 \\
\hline Khulna & 0.922 & 0.740 & 1.150 \\
\hline Rajshahi & 1.095 & 0.893 & 1.344 \\
\hline Sylhet & $0.647 * * *$ & 0.503 & 0.831 \\
\hline
\end{tabular}

Note: Level of significance $* * * \mathrm{p}<0.001$; and $* \mathrm{p}<0.05$.

Women's education appeared as a more powerful predictor than that of husband for childbearing among adolescents and teenage motherhood. For instance, adolescents with at least secondary level of education were 47.4 per cent less likely to begin childbearing before age 19, while the corresponding 
odds for husbands with at least secondary education was 26.7 per cent (Table 5). The effect of secondary level of education became apparent for adults, while the husband's education appeared to be less effective after controlling over other confounding factors (Table 6). The findings further reveal that compared to the adolescents who had no formal schooling, the adolescents who had at least secondary education were 12.4 per cent less likely to begin childbearing (Table 5), while this relationship was not found to be significant between adolescents who had primary education (Table 6). The adolescents with husbands who had primary education and had at least secondary education were significantly $(p<0.10)$ less likely to begin childbearing before age 19 as compared to those whose husbands had no formal education. The more was the women's level of education, the lesser was the likelihood of teenage motherhood among adults.

Although religion did not show to have net effect on childbearing among adolescents, it appeared as a vital predictor for teenage motherhood for elder women (Table 6). The non-Muslim women were significantly $(p<0.001) 45.3$ per cent less likely to have childbirth at adolescence than their peer Muslim counterparts. Sex of household head appeared to be an insignificant predictor for the onset of childbearing during adolescence. Ever use of a contraceptive method showed that it had net significant effect on teenage childbearing. The adolescents and adults who ever used any contraceptive method were 2.6 times and 3.0 times as likely as to initiate childbearing in their teen ages than those who never used any contraceptive method. The findings indicate that the effect of ever use of contraceptive method was more pronounced among adults than the adolescents. Wealth index, as expected, showed to have significant negative effect on adolescent motherhood. The more was the wealth, the lesser was the probability to begin childbearing during adolescence. Regional effect on the onset of childbearing was more pronounced among adolescents than the adult women. For instance, as compared to adolescents of Barisal, the odds of initiation of childbearing during the adolescents among women of Chittagong, Rajshahi and Sylhet were 2.2, 1.9 and 2.6 times. Although the likelihood of being a mother was higher among adolescents of Dhaka and Khulna divisions, however, the effect was not significant when other variables were held constant (Table 5). Besides, the adult women of Sylhet division as compared to those of Barisal division were 35.3 per cent less likely to be an adolescent mother. The effects of other administrative regions showed to have no significant effect on adolescent childbearing amongst the adult women (Table 6).

\section{Discussion and conclusion}

This study investigates the factors affecting adolescent motherhood in Bangladesh using the nationally representative 2007 BDHS data. The results of the multivariate analyses for adolescents and adult women have been discussed side by side to improve understanding the recent and the most recent past situation of adolescent childbearing in Bangladesh. The findings of the study suggest that adolescent childbearing and adolescent motherhood are still 
common and deeply embedded among Bangladeshi women. The prevalence of adolescent childbearing is highest in Bangladesh among Asian countries. The women in Bangladesh become mother at their very early ages with the large majority of women started bearing children before they reach at the age of twenty (Singh 1998). It is evident that the use of contraceptive method among teenage married females is relatively low compared to their adult counterparts, resulting in higher likelihood of initiation of childbearing at a very early age in Bangladesh, with the large majority of women becoming mothers during adolescence (Islam 1999).

Findings showed that, 62.0 per cent of the adult women aged $20-49$ became mother before they reach at age 19 . The prevalence of motherhood at adolescence among teen agers was 69.0 per cent. In addition, three out of four births of the adolescent mothers were planned, and one-fourth was mistimed. These findings suggest that adolescent childbearing and adolescent motherhood are highly valued in Bangladesh. The study did not find any apparent decreasing trend of childbearing at teen ages by five-year age cohorts in the adult women age 20-45. However, the findings suggest that the rate of adolescent childbearing among women aged 20-44 had slightly decreased compared to the women aged 45-49. Besides, the prevalence and likelihood of initiation of childbearing before age 19 showed fluctuations among women age 20-44. The insignificant odds ratios for childbearing among women age 20-29 compared to those age 45-49 suggest that early childbearing did not decrease significantly between the young and the elder women. Earlier studies showed that the trend of the effects of typical demographic and socio-economic factors on childbearing pattern among the women in Bangladesh did not show a substantial change (Asaduzzaman and Khan 2009). Using the un-weighted BDHS data, a more recent study revealed that adolescent childbearing has even increased in Bangladesh from 67.1 per cent in 2004 to 70.3 per cent in 2007 (Haque 2011). Thus, our findings are consisted with these earlier studies.

A comparison between BDHS data and that of Health and Demographic Surveillance System (HDSS) - Matlab, suggests that teenage fertility was half in Matlab area than in national level (58 vs. 126 per 1000). In Matlab, the TFR was 2.5 births per woman in 2009. Moreover, the median age at first marriage for all ever married females of reproductive age was recorded higher in Matlab compared to that of national level (19.0 years vs. 15.3 years) (ICDDR,B 2011; NIPORT et al. 2009). The large variation in adolescent's fertility between national level and Matlab area may be attributed to underreporting of age in BDHS data. HDSS data for Matlab area may be more accurate as civil registration is maintained and age of the women is known by date of birth. Traditionally, where vital registration is not maintained, birth history data are associated with various kinds of errors such as reporting errors, recall lapse errors, displacement of births from one period to another period. Furthermore, differential omission may also cause problems for fertility estimation (Kabir and Chowdhury 2004), age at first marriage, age at first birth etc.

Childbearing at very early age is an alarming issue for developing countries like Bangladesh as it contributes to young age structure and thus population momentum. Future population growth will be mostly from population 
momentum, and a way to minimize the growth is raising average age of childbearing through delaying marriage and first birth, and strengthening family planning programme to minimize unwanted pregnancy. While child bearing is confined to marriage, and date of marriage marks the onset of reproduction, persistently early female marriage delays fertility decline. Although major investments in female secondary schooling are showing impressive results, however, due to poor completion rates of schooling resulting from poor social insecurity and lack of rural employment opportunities, girls are still marrying below the legal minimum age of 18 years in Bangladesh.

The findings indicate that women's education had significant depressive influence on the probability of adolescent childbearing. Overall, women's secondary or higher education acted as catalyst toward delayed childbearing in Bangladesh. The findings may be explained by the way that the women who had at least secondary level of education have postponed substantial times during their schooling and married at later ages compared to their lesser educated counterparts. Although husband's secondary and higher education played a vital role to begin childbearing in later ages among adolescents, however, its effect was found to be less pronounced among older women. The husbands who had secondary or higher education are aware regarding adverse outcome of early childbearing and hence are more likely to delay childbearing of their wives as compared to husbands who had no formal education. The effect of primary education showed to have little influence on the timing of childbearing. Our findings are consistent with studies conducted elsewhere (Gaudie et al. 2010; Choe et al. 2004; Gupta and Mahy 2003).

Current place of resident showed to have little significant influence on teenage childbearing. One of the possible reasons is that government provided female stipend programme in Bangladesh has substantially reduced wide gap of educational attainment of adolescents of rural and urban areas. Another possible reason may be that many women including adolescents are migrated in urban areas with their spouses for better livelihood. Migration from rural to urban areas and closer gap in secondary level of education may have made a balance in adolescent childbearing among rural and urban Bangladeshi women. Childhood place of residence and religion are two important determinants in adolescent motherhood. These two variables also reflect woman's cultural and familial background where she spent her formative years as a child and teenagers. It is very plausible that her basic values and expectations about marital life, education and career are all affected by the type of family where she grew up. The family where woman grew up may help to determine how she evaluates the costs and benefits of timing childbearing. The women resided in rural areas were tended to be more likely to have childbirth earlier than those who resided in urban areas in childhood period. The Muslim women were also more likely to have childbirth earlier than the non-Muslim women. It is plausible that, the normative pressure, traditional belief and cultural practice of lead Muslim women to have early birth compared to their non-Muslim counterparts which also reflected from the findings of the study. This finding is consistent with an earlier study conducted on Brazilian women (Gigante et al. 2004). 
Along with early marriage, lower use rate of contraceptive method among the married teen agers compared to the adult women is a vital predictor of adolescent motherhood in Bangladesh. Most of the women in Bangladesh initiate contraceptive use after they have first childbirth. Our findings revealed that the adolescents and adult women who had ever used any contraceptive method were more likely to initiate childbearing at adolescence period. This may be explained by the way that many of the women initiated contraceptive use after they had completed fertility as their desired size and some wanted to make significant space to delay the next birth. This finding is consistent with a recent study conducted on Bangladeshi women (Haque 2011).

The effect of wealth index on adolescent childbearing was vague. The richest compared to the poorest were less likely to be adolescent mother. This is partly attributed to the fact that the women from richest family are more educated, more conscious about the timing of childbearing and are also better informed regarding adverse effect of early motherhood compared to women of other wealth quintiles. The estimated odds ratios for other wealth quintiles than the richest did not substantially predict significant difference on adolescent childbearing. However, when teen mothers as compared to their matched counterparts who are similar in every observed preexisting characteristic except for teenage childbearing status, teen motherhood still has modest but significant negative effects on various early socioeconomic outcomes. This finding of the study is also consistent with earlier studies conducted elsewhere (Gaudie et al. 2010; Lee 2010; Gigante et al. 2004).

The region of place indicates that compared to the women of Barisal division, the risk of adolescent childbearing of the women of Chittagong and Sylhet divisions were lower and that of the women of Khulna division was higher, while other two divisions Dhaka and Rajshahi did not show substantial difference in adolescent childbearing. The higher and lower risks of adolescent childbearing in the regions are partly due to lower and higher age at first marriage of women in those regions. The cultural tradition across the regions and prevailing socioeconomic status may be also partly attributed to the adolescent motherhood of the women. However, most of the findings of the study are consistent with those conducted on the women of Sub-Saharan Africa (Gupta and Mahy 2003).

\section{Limitations}

The study has several limitations. First, even though the survey included a wide range of retrospective questions on birth histories of women, most background characteristics were not collected with individual life histories. Such as, many literatures reveal that parental education and mothers' age at first birth are closely related to the age at first birth of the child of her daughter. Those variables were not included in the survey questionnaire. Second, of the married adolescents aged 15-19, some were already mothers, some were pregnant for the first time and some did not yet initiate motherhood. This picture does not portray the fact that exactly what proportion of adolescents initiates motherhood at their adolescence, because, some of them would become mother had they were surveyed after completing adolescence. Third, 
the retrospective survey suffers from recall bias. The age at first birth of child reported by the women may not be free of underreporting. It is a common phenomenon of developing countries where vital registration system is not followed. Such underreporting may bias the estimates and hence caution is warranted when interpreting the results. Despite these limitations, the strength of the study is that it dealt with a reliable nationally representative large data set which is mostly used in such demographic studies.

\section{Recommendations}

The findings of the study suggest that adolescent childbearing is a common phenomenon in Bangladesh. Early marriage is directly associated with early childbearing. Higher incidents of early marriage of Bangladeshi girls' result higher prevalence of teenage motherhood. This finding indicates poor status of women, poor initiation of adulthood and poor starts of conjugal life. In view of high incidence of adolescent childbearing in Bangladesh, immediate policy and special programmatic measures should be undertaken to prevent the child marriage. Adolescents and their guardians should be made more aware of the adverse health outcomes, social and economic consequences of early marriage and early childbearing. Despite of wide expansion of female stipend programme in the country, early marriage and early childbearing have not been substantially decreased over the decades. Programmes should be undertaken to remain girls in school for a longer duration not only to raise the age at first marriage and age at first birth, also to their overall development, as education is the basic key to social and individual development. In addition, not the level of education by itself, but mainly the way in which woman's education is evaluated on the labour market, is important in treating the effect of education on the timing of first birth (Kantorova 2002). The prevailing social and cultural norms are still favouring girls to get marry earlier and to have early childbirth. To reduce early marriage, the ordinance of legal age at marriage should be properly implemented across regions and rural-urban areas of Bangladesh. It is, therefore, crucial to target young women with accurate information on reproductive health to provide them with basic life skills and reproductive health in order to enable them to avoid early sexual activity and ultimately early childbearing. In addition, user- friendly reproductive health services should be availed to the young women who are sexually active to enable them to avoid unwanted and mistimed births (Ikamari 2008). Social movement and social campaigns may play effective role in reducing adolescent motherhood highlighting the adverse outcomes of early marriage, long run health consequences of mothers and child. If the trends of adolescent childbearing continue it would be difficult to ensure healthy life of mothers and child and to achieve the replacement level of fertility in Bangladesh.

\section{References}

Alam, N. 2000. Teenage motherhood and infant mortality in Bangladesh: Maternal agedependent effect of parity one. Journal of Biosocial Science 32(2):229-36. 
AGI (Alan Guttmacher Institute). 1998. Into a new world: Young women's sexual and reproductive lives. New York: Alan Guttmacher Institute.

Asaduzzaman, M. and M.H.R. Khan. 2009. Identifying potential factors of childbearing in Bangladesh. Asian Social Science 5(3):147-54.

Barkat, A. and M. Majid. 2003. Adolescent Reproductive Health in Bangladesh: Status, Policies, Programs and Issues. POLICY Project Report, USAID Asia/Near East Bureau.

Birkeland, R., J.K. Thompson, and V. Phares. 2005. Adolescent motherhood and postpartum depression. Journal of Clinical Child and Adolescent Psychology 34(2):292-300.

Bogue, D.J., K. Oettinger, M. Thomson, and P. Morse. 1977. Adolescent Fertility. Proceedings of the First International Conference on Adolescent Fertility. Chicago: Community and Family Study Center.

Bosch, A.M., F.J. Willekens, A. Baqui, J.K.S. Van Ginneken, and I. Hutter. 2008. Association between age at menerche and early life nutritional status in rural Bangladesh. Journal of Biosocial Science 40(2):223-37.

Choe, M.K., S. Thapa, and V. Mistra. 2004. Early marriage and early motherhood in Nepal. Journal of Biosocial Science 37(2):143-62.

Cleland, J., J.F. Phillips, S. Amin, and G.M. Kamal. 1994. Reproductive Change in Bangladesh: Success in a Challenging Environment. Washington, DC: World Bank.

Devine, C.M., C.F. Bove, and C.M. Olson. 2000. Continuity and change in women's weight orientations and lifestyle practices through pregnancy and the postpartum period. Social Science and Medicine 50(4):567-82.

Deutsch, F.M., D.N. Ruble, A. Fleming, J. Brooks-Gunn, and C. Stangor. 1988. Information seeking and maternal self definition during the transition to motherhood. Journal of Personality and Social Psychology 55(3):420-31.

ESCAP (Economic and Social Commission for Asia and the Pacific). 1992. Adolescent Reproductive Behaviour: Asian and Pacific Region. Population Research Leads No. 41. Bangkok: ESCAP.

Foix-H'Helias, L. and B. Blondel. 2000. Changes in risk factors of preterm delivery in France between 1981 and 1990. Paediatric and Perinatal Epidemiology 14(4):314-23.

Gage, A. 1995. The Social Implications of Adolescent Fertility. Paper presented at the International Union for the Scientific Study of Population (IUSSP), United Nations Children's Fund Seminar on Demography and Poverty, Florence, Italy.

Gaudie, J., F. Mitrou, D. Lawrence, F.J. Stanley, S.R. Silburn and S.R. Zubrick. 2010. Antecedents of teenage pregnancy from a 14-year follow-up study using data linkage. BMC Public Health 10:63.

Gigante, D.P., C.G. Victora, H. Gonçalves, R.C. Lima, F.C. Barros, and K.M. Rasmussen. 2004. Risk factors for childbearing during adolescence in a population-based birth cohort in southern Brazil. Pan American Journal of Public Health 16(1):1-10.

Gogna, M., G. Binstock, S. Fernandez, I. Ibarlucia, and I. Zamberlin. 2008. Adolescent pregnancy in Argentina: Evidence-based recommendations for public policies. Reproductive Health Matters 16(31):192-201.

Gupta, N. and M. Mahy. 2003. Adolescent childbearing in sub-Saharan Africa: Can increased schooling alone raise ages at first birth? Demographic Research 18(4):93-106.

Haque, M.N. 2011. Levels, trends and determinants of adolescent childbearing in Bangladesh. International Journal of Current Research 2(1):170-5.

Hayes, C. 1987. Risking the Future: Adolescent Sexuality, Pregnancy and Childbearing. Washington: National Academic Press.

Ikamari, L.D.E. 2008. Regional variation in initiation of childbearing in Kenya. African Population Studies 23(1):25-40.

ICDDR,B (International Centre for Diarrhoeal Diseases Research, Bangladesh) .2011. Health and Demographic Surveillance System - Matlab: Registration of Health and Demographic Events 2009. Vol. 43, Scientific Report No. 114, Dhaka: ICDDR,B. 
Islam, M.M. 1999. Adolescent Childbearing in Bangladesh. Asia Pacific Population Journal 14(3):73-87.

Jennings, B. and M. Edmundson. 1980. The postpartum period: After confinement, the fourth trimester. Clinical Obstetrics and Gynecology 23(4):1093-1103.

Jimenez, M.A., A.R. Martin, and J.R. Garcia. 2000. Comparing the biological and psychological risks of pregnancy between groups of adolescents and adults. European Journal of Epidemiology 16(6):527-32.

Kabir, M. and M.A.A.M. Chowdhury. 2004. Plateauing fertility in Bangladesh: Correlates and proximate determinants, in Fertility transition in Bangladesh: Evidence and implication, edited by U. Rob, M.N. Ameen, and N. Piet-Pelon. Dhaka: UNFPA.

Kantorova, V. 2002. Education and Entry into Motherhood: The Czech Republic During State Socialism and the Transition Period (1970-1997). Paper presented at the workshop on "Education and Postponement of Maternity." Amsterdam: October 25-26.

Khan, S. and V. Mishra. 2008. Youth Reproductive and Sexual Health. DHS Comparative Reports No. 19. Calverton, MD: Macro International Inc.

Lee, D. 2010. The early socioeconomic effects of teenage childbearing: A propensity score matching approach. Demographic Research 23(25):697-736.

Lee, M.C., L.A. Suhng, T.H. Lu and M.C. Chou. 1998. Association of parental characteristics with adverse outcomes of adolescent childbearing. Family Practice 15(4):336-42.

Magadi, M., A. Agwanda, F. Obare, and N. Taffa. 2003. Comparing maternal health indicators between teenagers and older women in sub-Saharan Africa: Evidence from DHS. Working Paper No. A03/18, Southampton Statistical Sciences Research Institute.

Menken, J. 1980. The health and demographic consequences of adolescent pregnancy and childbearing, in Adolescent Pregnancy and Childbearing: Findings from Research, edited by C.S. Chilman. Washington DC: US Department of Health and Human Services.

NIPORT (National Institute of Population Research and Training). 2009. Bangladesh Demographic and Health Survey 2007. Dhaka, Bangladesh and Calverton, MD: National Institute of Population Research and Training, Mitra and Associates, and Macro International.

Orvos, H., I. Nyirati, J. Hajdu, A. Paul, T. Nyari, and L. Kovacs. 1999. Is adolescent pregnancy associated with adverse perinatal outcome? Journal of Perinatal Medicine 27(3):199-203.

Phipps, M.G. and M.F. Sowers. 2002. Defining early adolescent childbearing. American Journal of Public Health 92(1):125-8.

Senderowitz, J. and J.M. Paxman. 1985. Adolescent fertility: Worldwide concerns. Population Bulletin 40(2):3-49.

Singh, S. 1998. Adolescent childbearing in developing countries: A global review. Studies in Family Planning 29(2):117-36.

Sing, S. and R. Samara. 1996. Early marriage among women in developing countries. International Family Planning Perspectives 22:148-57,175.

Smith, G. and J. Pell. 2001. Teenage pregnancy and risk of adverse perinatal outcomes associated with first and second births: Population based retrospective cohort study. BMJ 323(7311):476.

Sutay, Y. 2010. Changes in Adolescent Childbearing in Morocco, Egypt and Turkey. DHS Working Papers No. 75. Calverton, MD: ICF Macro.

Tsai, T.S., J.Y. Chen and M.C. Lee. 2001. Reproductive outcomes and infant health in adolescent pregnancy in Taichung city. Acta Paediatrica Taiwan 42(3):151-7.

Voydanoff, P. and B.W. Donnelly. 1990. Adolescent Sexuality and Pregnancy. Newbury Park: Sage Publications. 
Wasunna, A. and K. Mohammed. 2002. Low birth weight babies: Socio-demographic and obstetric characteristics of adolescent mothers at Kenyatta National Hospital, Nairobi. East African Medical Journal 79(10):543-56.

Wulf, D. and S. Singh. 1991. Sexual activity, union and childbearing among adolescent women in the Americans. International Family Planning Perspectives 17(4):137-44.

Zabin, L. and K. Kiragu. 1998. The health consequences of adolescent sexual and fertility behavior in Sub-Saharan Africa. Studies in Family Planning 29(2):210-32.

Zabielski, M.T. 1994. Recognition of maternal identity in preterm and full-term mothers. Maternal-Child Nursing Journal 22(1):2-36. 